\title{
ORAL MYIASIS- A RARE CASE REPORT
}

\author{
Rituparna Saha1, Lido Kamgo², Aniruddha Basak ${ }^{3}$
}

1 Postgraduate Trainee, Department of ORL \& HNS (ENT), Regional Institute of Medical Sciences, Imphal. ${ }^{2}$ Postgraduate Trainee, Department of ORL \& HNS (ENT), Regional Institute of Medical Sciences, Imphal. ${ }^{3} M S$, Department of General Surgery, Regional Institute of Medical Sciences, Imphal.

HOW TO CITE THIS ARTICLE: Saha R, Kamgo L, Basak A. Oral myiasis- A rare case report. J. Evolution Med. Dent. Sci. 2017;6(77): 5513-5515, DOI: $10.14260 /$ Jemds/2017/1197

\section{PRESENTATION OF CASE}

A 30-year-old male was brought in the Dept. of Otorhinolaryngology \& Head/Neck Surgery, RIMS with a complaint of maggots coming out from mouth along with ulceration, swelling \& necrosis of gingival area. There is history of alleged RTA 3 years back for which he underwent left-sided frontotemporoparietal craniectomy followed by cranioplasty. At present, patient is in vegetative state with spontaneous eye opening and spastic hemiplegia. On local examination, there was severe halitosis and poor oral hygiene with generalised periodontitis. Upper gingiva was detached and lifted from the alveolar bone with deep pockets in relation with upper left incisor \& canine teeth which were covered by necrotic tissue along with slough. The palatal soft tissue was perforated near the incisor region with bony defect in hard palate. On close examination, numerous maggots were seen moving and coming out of the lesion. The clinical presence of the maggots and the examination of the maggots confirm the diagnosis of oral myiasis. Cotton bud impregnated with turpentine oil was placed at the orifice of the socket for approximately 10 minutes. Around 20 maggots were manually removed with tissue holding forceps. Necrotic areas are irrigated with hydrogen peroxide and Betadine solution along with suction machine. On the next day, the patient again came with his attendant complaining of leftover maggots in oral cavity. Irrigation and lavage of the wound continued for one week along with conservative treatment with broad-spectrum oral antibiotics. Oral hygiene instructions to the guardians were carried out extensively.

\section{DIFFERENTIAL DIAGNOSES}

- Squamous cell carcinoma involving oral cavity.

- Cancrum Oris.

- Acute necrotising fasciitis.

- Advanced periodontal disease.

- Foreign Body Reaction.

- Tungiasis.

- Leishmaniasis.

- Early Dracunculosis.

\section{CLINICAL DIAGNOSIS}

Oral Myiasis.

Financial or Other, Competing Interest: None

Submission 16-08-2017, Peer Review 13-09-2017,

Acceptance 19-09-2017, Published 25-09-2017.

Corresponding Author:

Dr. Rituparna Saha,

Ladies PG Hostel, No. 1

RIMS, Imphal-795004,

Lamphelpat.

E-mail: drrituparnasaha07@gmail.com

DOI: $10.14260 /$ jemds $/ 2017 / 1197$

\section{(c) $(i)$}

\section{PATHOLOGICAL DISCUSSION}

"Lice, ticks, mosquitoes, and bedbugs will always lurk in the shadows when neglect, poverty, famine, or war lets down the defences." -Hans Zinsser (American bacteriologist, 18781940. Quoted from his book "Rats, Lice and History"). Myiasis was first described by F. W. Hope in 1840. Myiasis is derived from the Greek word "myia, " meaning fly and "asis, " meaning disease. ${ }^{1}$ Myiasis is defined by Zumpt as an infestation of live human and vertebrate animals by the larva of the dipterous fly, feeding on the host's dead or living tissue, liquid body substances or ingested food ${ }^{2}$ and is found to have been reported mainly in the warm and humid tropical countries. $^{3}$

Myiasis can be classified depending upon the condition of involved tissue ${ }^{4}$ into-

- Accidental Myiasis: Larvae are ingested along with food producing infection.

- Semispecific Myiasis: The larvae are laid on necrotic tissue in wounds.

- $\quad$ Obligatory Myiasis: Larvae affect undamaged skin.

\section{Clinically 4}

- Primary: Caused by biophagous larvae (feed on living tissues) also called as obligatory myiasis.

- Secondary: Caused by the necrobiophagous larvae (feed on dead tissues) also called as facultative myiasis.

\section{Based on Anatomic site}

- Cutaneous myiasis.

- Myiasis of external orifices.

- Myiasis of internal organs.

The most common anatomic sites for myiasis are the nose, eye, lung, ear, anus, vagina and more rarely, the mouth. ${ }^{5}$ Oral myiasis is very rare and was first described by Laurence in 1909.6 Incidence of oral myiasis as compared to that of cutaneous myiasis is less as the oral tissues are not permanently exposed to the external environment. ${ }^{7}$ Predisposing factors of oral myiasis can be poor oral hygiene, mouth breathing, halitosis, oral suppurative lesions, trauma, alcoholism, senility, mental retardation, and neurological deficit. ${ }^{8}$ Some cases of oral myiasis are associated with Cancrum oris, tooth extraction, mandibular fracture, anterior open bite, incompetent lips, cerebral palsy and patients undergoing mechanical ventilation. ${ }^{9}$

Musca nebulo is the commonest Indian house fly. They are seen in abundance in human dwellings and are very active during summer and rainy season. ${ }^{10}$ The life cycle of a fly begins with the egg stage followed by the larva, the pupa and finally the adult fly. The conditions required for egg laying and survival of the larvae are moisture, necrotic tissue 
and suitable temperature. ${ }^{11}$ The larvae hatch from the eggs in about 12-24 hours after they are laid in the necrotic tissues, soon after which they burrow into the surrounding tissues causing inflammation. The larvae remain parasitic in the tissue for 5-7 days till they mature and leave the body for the pupal stage. They may diffuse to the paranasal sinuses, nasolacrimal duct, orbit, skin and occasionally intracranial structures. ${ }^{12}$ The larvae have backward directed segmental hooks with which they anchor themselves to the surrounding tissue. They are photophobic and tend to hide deep into the tissues for a suitable niche to develop into pupa.13 The present case also showed the larvae burrowed deep inside the socket. These larvae release toxins to destroy the host tissue. ${ }^{14}$ Proteolytic enzymes released by the surrounding bacteria decompose the tissue and the larvae feed on this rotten tissue. ${ }^{15}$ The infected tissue frequently releases a foulsmelling discharge. ${ }^{13}$

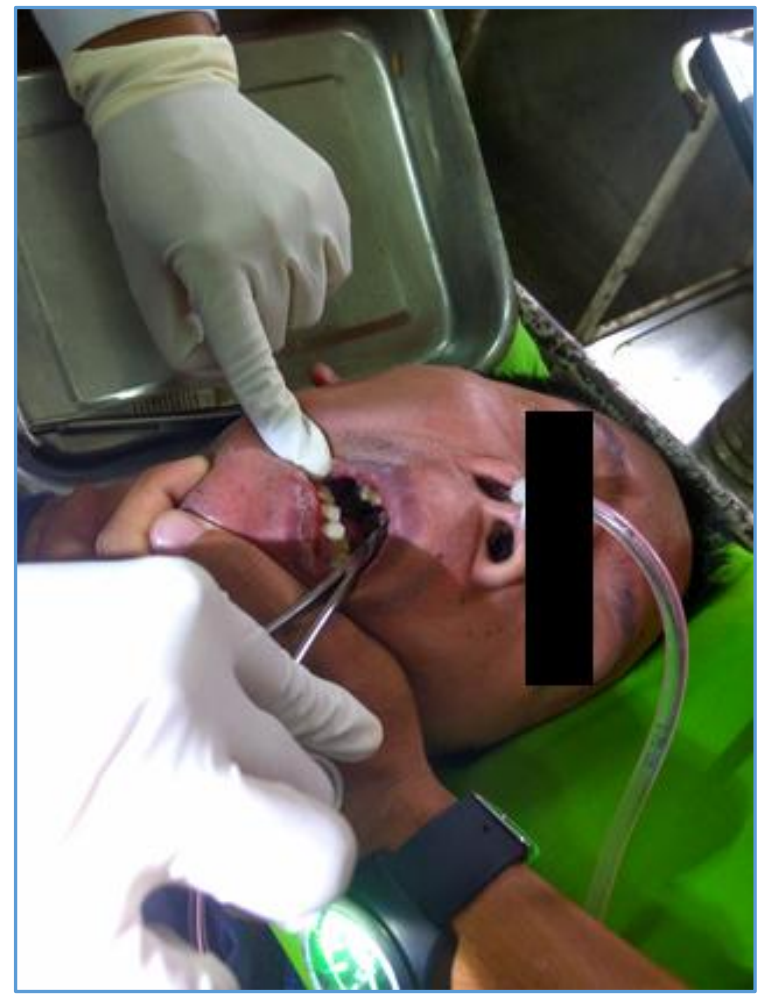

Figure 1. Showing Necrosis of Gingiva along with Upper Alveolar Process following Maggot Infestation

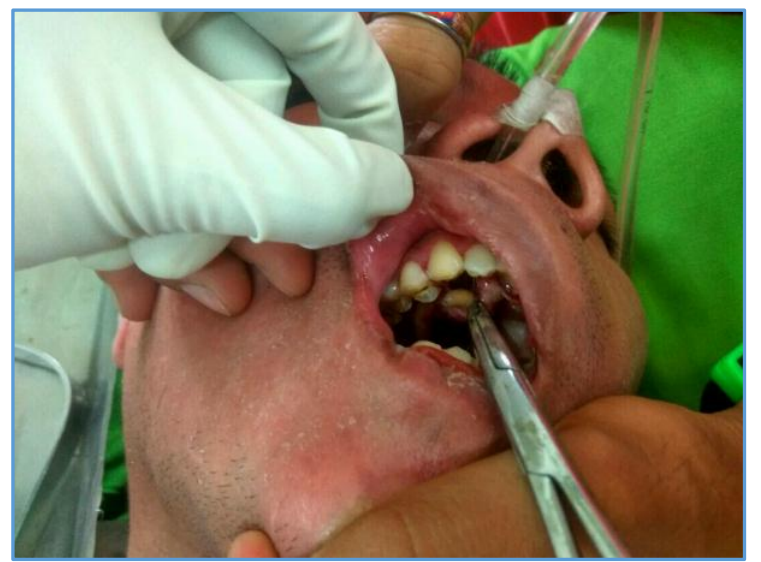

Figure 2. Showing Removal of Maggots by Artery Forceps

\section{DISCUSSION OF MANAGEMENT}

The traditional management of myiasis is the mechanical removal of the maggots. In case of multiple larvae and in advanced stages of development and tissue destruction, local application of several substances such as oil of turpentine, larvicidal drug like Negasunt $\AA^{\circledR}, 16$ mineral oil, ether, chloroform, ethyl chloride, mercuric chloride, creosote, saline, phenol, calomel, olive oil, iodoform, can be used to ensure complete removal of all larvae. ${ }^{17} \mathrm{~A}$ technique for removal of the maggots was occlusion of the infested wound by materials like paraffin to suffocate and force the maggots to come out to the surface. ${ }^{18}$ Systemic ivermectin, (semisynthetic macrolide antibiotic) may give favourable results in more severe cases. ${ }^{19}$ Systemic therapy with Doxycycline, metronidazole and ivermectin are also successfully used in oral myiasis. $0.2 \%$ of chlorhexidine mouth wash can be used to maintain good oral hygiene for these patients. Mechanism of action of ivermectin is by release of GABA, which aid in blocking the nerve endings of the larvae leading to death. ${ }^{20}$ Dose of ivermectin in oral myiasis is 200 to $400 \mathrm{mcg} / \mathrm{kg}$ body weight. The possible complications which are reported in the literature are neurotoxicity since the drug can cross the blood brain barrier and interaction with other systemic drugs. Lima junior et al reported the use of nitrofurazone topical application for the non-surgical management of oral myiasis in 2010. Nitrofurazone is a topical antiparasitic agent whose derivatives possess antibacterial, antiprotozoal and antiparasitic properties. Nitrofurazone is used at a concentration of $0.2 \%$, which was used topically for 3 consecutive days. ${ }^{21}$ Riberio et al reported the use of $50 \%$ of sulphuric ether for 1 minute for the asphyxiation of maggots along with $0.12 \%$ chlorhexidine at the end of mechanical removal. ${ }^{20}$

Though oral myiasis is a rare condition Otorhinolaryngologists, Dentists and medical personnel taking care of old or debilitated patients with neurologic deficit who are dependent on others for maintaining basic hygiene should suspect the possibility of infestation with Dipteran flies' larvae. Prompt diagnosis and adequate treatment should be started at the earliest to prevent local tissue destruction and systemic invasion of blood vessels, nerves and skin. There is no standard treatment protocol. Manual removal of maggots along with surgical debridement of wound, systemic antibiotics to treat secondary infections and most importantly maintaining proper oral hygiene give best possible outcome.

\section{FINAL DIAGNOSIS}

Secondary Oral Myiasis by Dipteran larvae in a male with spastic hemiplegia following RTA.

\section{REFERENCES}

[1] Zumpt F. Myiasis in man and animals in the old world: a textbook for physicians, veterinarians and zoologist. London, UK: Butterworth 1965: p. 109.

[2] Agrawal B, Dhole A, Deora S, et al. Oral myiasis: a case report. Int J Dent Case Reports 2012;2(3):61-5.

[3] Bhatt AP, Jayakrishnan A. Oral myiasis: a case report. Int J Paediatr Dent 2000;10(1):67-70. 
[4] Gomez RS, Perdigão PF, Pimenta FJ, et al. Oral myiasis by screwworm Cochliomyia hominivorax. British Journal of Oral and Maxillofacial Surgery 2003;41(2): 115-6.

[5] Abdo EN, Sette-Dias AC, Comunian CR, et al. Oral myiasis: a case report. Med Oral Patol Oral Cir Bucal 2006;11(2):E130-1.

[6] Lawrence SM. Dipterous larvae infection. Br Med J 1909;9:88.

[7] Aguiar AM, Enwonwu CO, Pires FR. Noma (Cancrum oris) associated with oral myiasis in an adult. Oral Dis 2003;9(3):158-9.

[8] Rossi-Schneider T, Cherubini K, Yurgel LS, et al. Oral myiasis - a case report. J Oral Sci 2007;49(1):85-8.

[9] Droma EB, Wilamowski A, Schnur H, et al. Oral myiasis: a case report and literature review. Oral Surg Oral Med Oral Pathol Oral Radiol Endod 2007;103(1):92-6.

[10] Sharma J, Mamatha GP, Acharya R. Primary oral myiasis: a case report. Med Oral Patol Oral Cir Bucal 2008;13(11):E714-6.

[11] Jain S, Gupta S, Jindal SK, et al. Oral myiasis in a cerebral palsy patient: a case report. J Clin Exp Dent 2010;2(2):e110-2.

http://www.medicinaoral.com/odo/volumenes/v2i2/ jcedv2i2p110.pdf

[12] Sharma H, Dayal D, Agrawal SP. Nasal myiasis: review of 10 years of experience. The Journal of Laryngology and Otology 1989;103(5):489-91.
[13] Ramli R, Rahman RA. Oral myiasis: case report. Malaysian J Med Sci 2002;9(2):47-50.

[14] Sood VP, Kakar PK, Wattal BL. Myiasis in otorhinolaryngology with entomological aspects. J Laryngol Otol 1976;90(4):393-9.

[15] Lim ST. Oral myiasis-a review. Singapore Dent J 1974;13(2):33-4.

[16] Zeltser R, Lustmann J. Oral myiasis [corrected and issued with original paging in Int J Oral Maxillofac Surg 1988 Oct;17(5):288-9]. Int J Oral Maxillofac Surg 1989;18(2):288-9.

[17] Henry J. Oral myiasis: a case study. Dent Update 1996;23(9):372-3.

[18] McGraw TA, Turiansky GW. Cutaneous myiasis. J Am Acad Dermatol 2008;58(6):907-26.

[19] Shinohara EH, Martini MZ, de Oliveira NHG, et al. Oral myiasis treated with ivermectin: case report. Braz Dent J 2004;15(1):79-81.

[20] Ribeiro AL, de Almeida TE, Lopes JS, et al. Oral myiasis: does an indication for surgical treatment still exist? Two case reports. Oral Surg Oral Med Oral Pathol Oral Radiol 2012;114(3):e10-e4.

[21] Júnior SML, Asprino L, Prado AP, et al. Oral myiasis caused by Cochliomyia hominivorax treated nonsurgically with nitrofurazone: report of 2 cases. Oral Surg Oral Med Oral Pathol Oral Radiol Endod 2010;109(3):e70-3. 